\title{
Analysis of the impact of transport accessibility on the cost of housing on the example of the city of Irkutsk
}

\author{
Maksim Sharov ${ }^{1, *}$ \\ ${ }^{1}$ Irkutsk National Research Technical University, 664074, Lermontova str., 83, Irkutsk, Russia
}

\begin{abstract}
Абстракт. The paper is devoted to the issues of estimation of transport accessibility of a territory, and also the influence of transport accessibility on cost of a square meter of housing. In particular, the dependence of the possible cost of one square meter on the value of transport accessibility is established.
\end{abstract}

The concept of sustainable development and a comfortable city presupposes the priority development of the systems of public passenger transport and "green" mobility (i.e. nonmechanized movements).

The priority development of the public passenger transport systems is provided by both technical solutions and urban planning. In modern foreign urban planning theory and practice, among the most common urban planning solutions that ensure the priority development of the public passenger transport systems are the following:

- mixed-use development, which reduces the need for long-distance travels;

- transit oriented development, focused on the public transportation, including the formation of attractive and comfortable environment, which houses the infrastructure of public passenger transport;

- increase in the intensity of use of territories adjacent to the corridors of public passenger transport.

With the improvement of the availability of public passenger transport, the attractiveness of the territories increases that causes concentration of the service sector institutions and places of employment.

In the global practice of urban planning, the availability of the territory is determined by the following factors: transport accessibility of the territories; availability of all necessary services; and presence of a sufficient number of public spaces.

In construction, the transport accessibility is a normative indicator of the time spent for the transport communications between different points within the systems of the group settlement [1]. When designing city streets and roads, one of the key parameters determining the quality of the urban road network is the time of communication between any two points of the city [2].

From the transport aspect of consideration of this issue, accessibility is the total time spent

*Corresponding author: sharov.maksim@gmail.com 
on traveling for any purpose (movements to the workplace, movements with cultural and domestic purposes, etc.).

The transport security of the urban and regional territories is used as one of the economic characteristics.

Improving transport accessibility is an important mechanism for implementing regional policies. Its rational use makes it possible to reduce disproportions in the territorial development of different districts of the city and the country as a whole, and to increase the attractiveness of remote and sparsely populated areas.

In this regard, it is necessary to note the need to develop modern criteria and standards for assessing the transport accessibility of the territory. In the Russian Federation, since the Soviet epoch, the building codes and regulations - SNiP 2.07.01-89 have been under operation, which set the requirements for the time to be spent for labor movements (Table 1). Even in the cities-millionaires, $90 \%$ of the working people should not spend more than 45 minutes on the road from their place of residence to the place of employment (one way).

Table 1. Time to be spent in the cities for travel from the places of residence to the places of work.

\begin{tabular}{|c|c|}
\hline Population of the city, thousand people. & Time to be spent, min \\
\hline 2000 & 45 \\
\hline 1000 & 40 \\
\hline 500 & 37 \\
\hline 250 & 35 \\
\hline 100 & 30 \\
\hline
\end{tabular}

For the intermediate values of the estimated urban population, the specified time-use rates should be interpolated. In addition, the SNiP states that:

- for daily visitors to work in the city center from other settlements, the specified rates of the time expenditures are allowed to be increased, but not more than twice.

- for the residents of rural settlements, the time to be spent for labor movements (pedestrian or using transport) within an agricultural enterprise, as a rule, should not exceed 30 minutes.

The cities with the population of more than 2 million people are included in the special group. The maximum allowable time in these cities should be determined by special justifications, taking into account the actual settlement, placement of the places of employment and the level of development of the transport systems.

The results of the questionnaire survey carried out by the Transport Laboratory of Irkutsk National Research Technical University in Irkutsk showed [6-9] that even the existing town planning standard of 38 minutes for the movements of people is realized only by $50 \%$. In general, the results of the assessment of the enlarged zones of Irkutsk are shown in the Figure 1. 


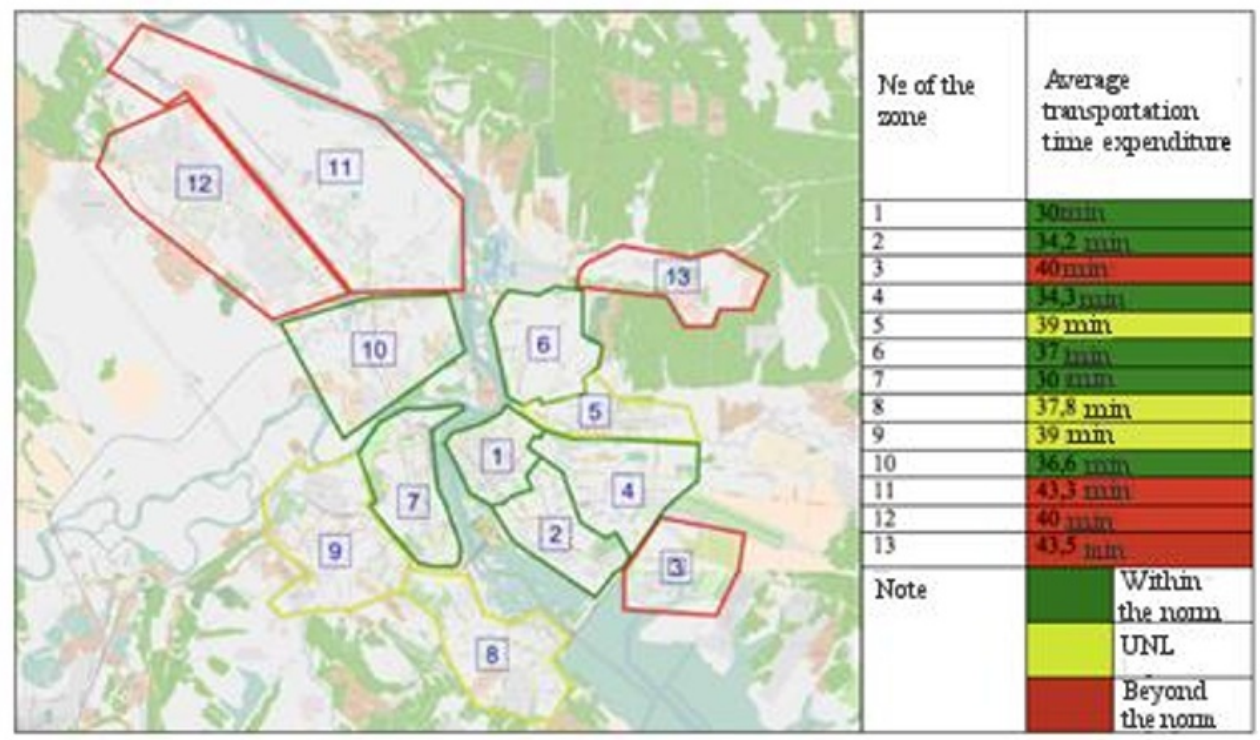

Fig. 1. Average time spent for movement with the labor purposes in the city of Irkutsk (one way).

The availability of such information makes it possible to assess the impact of transport accessibility on the cost of $1 \mathrm{sq}$. $\mathrm{m}$. of housing. Otherwise, it is very difficult to reveal the real impact of cost, since this is one of the main parameters for the formation of the cost of an apartment or office space.

Having analyzed the housing market of the city of Irkutsk, we have received the average cost of 1 sq. m. in newly built houses and on the secondary market (Figure 2).

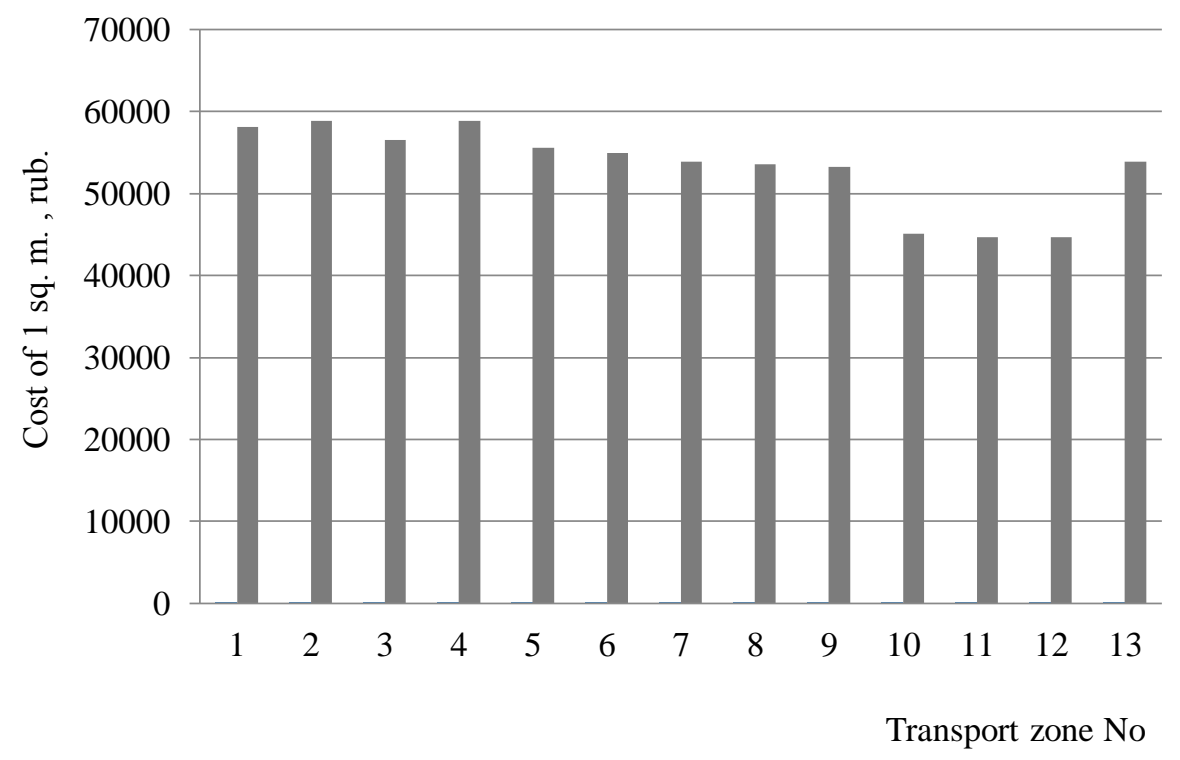

Fig. 2. Average cost of the square meter for the transport zones in Irkutsk.

The system for assessing the impact of the transport accessibility of a building (residential, business, and shopping and entertainment) on its market value includes a number 
of parameters:

- Remoteness from the central part of the city;

- The proximity of highways;

- The proximity of metro stations or ground transportation stops (in the case of the city of Irkutsk, the proximity of metro stations is not an estimation parameter);

- Presence of parking lots, car parks or garage cooperative;

- Developed system of the access roads (construction of new ones, reconstruction of old ones);

- The proximity of points of daily attraction (kindergartens, schools, medical centers, supermarkets, etc.);

- The impact of noise, vibration and exhaust gases [3].

In most research works, the emphasis is made on assessing the distance from the city center, since it is there that all the main objects of social gravity are concentrated.

In all countries, the level of transport accessibility is measured by the time required to travel from a specific point of the city to the outer limits of the central district. Ranking availability makes it possible to create the informed zoning of the urban territory.

As the level of transport access decreases, there is an increase in the expenditures for travel to the central part of the city, and the cost of the square meter will gradually decrease.

Our analysis showed that residential buildings located in the zones 1,2,4,6,7,8,10 will have the highest level of comfort in terms of the transport accessibility; the least comfortable will be residential buildings located in the zones 3,5,9,11, 12,13 (Figure 3). Accordingly, the location of the object will determine their cost.

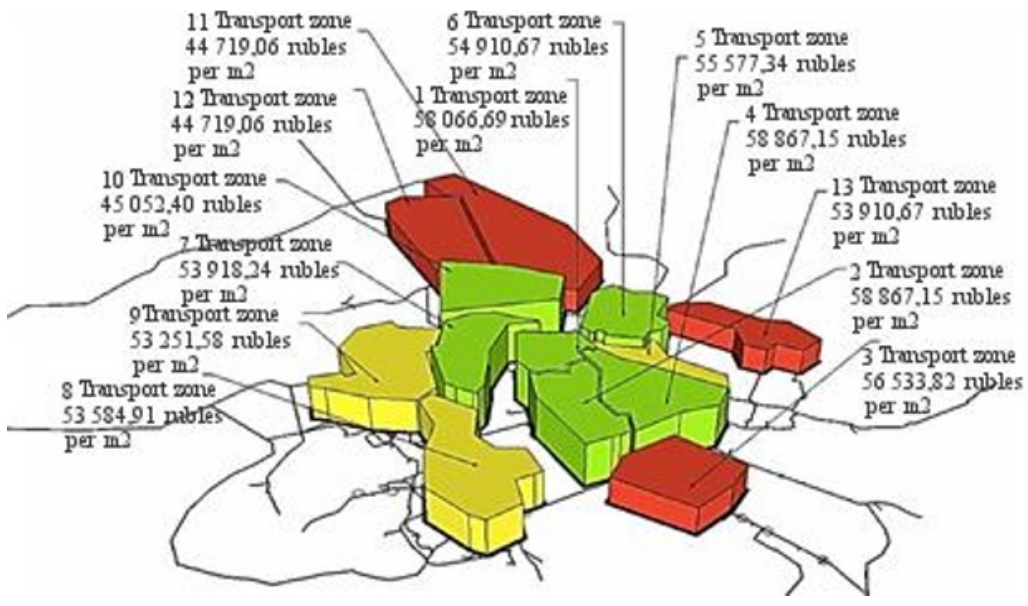

Note:

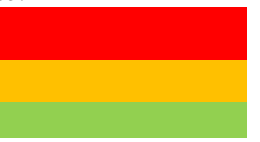

Satisfactory availability

Medium availability

High availability

Fig. 3 The cost of one square meter per transport zones in Irkutsk.

However, it should be noted that, despite the fact that the third transport zone has a low transport provision, the cost of one square meter there is 56,533.82 rubles. This is explained by the fact that there are mostly elite buildings, and people living in this area use individual transport.

Based on the analysis of the average market value of one square meter in the newly-built and secondary residential fund, it can be concluded that the most attractive for life are 
residential buildings located in the central part of the city.

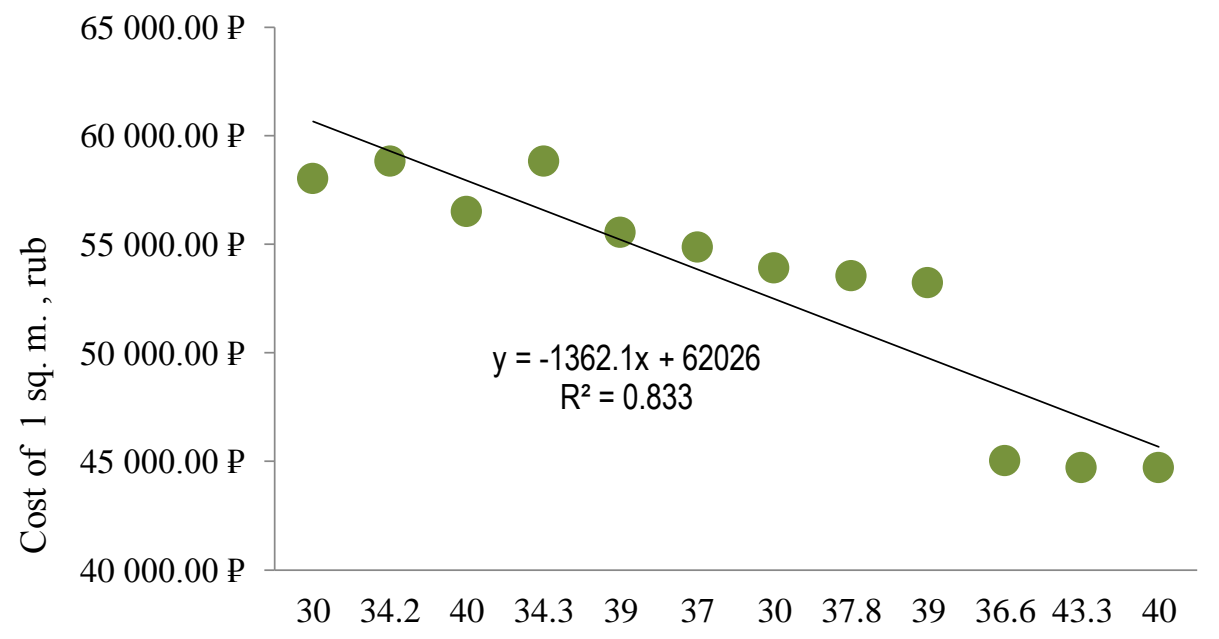

Time expenditures for the movement, min.

Fig. 4. Dependence of the cost of 1 square meter on the time spent for the movement.

Based on the analysis, the dependence of the time spent on the movements and the cost of one square meter of the residential real estate in the city of Irkutsk has been determined. For a functional explanation of the dependence of the cost of one square meter on the time spent for the movements for labor purposes, a trend line has been drawn up and the equation of this line has been obtained (Figure 4).

With the increase in the remoteness of the residential building from the geographical center of the city, the level of transport accessibility of the territory is decreasing, and as a result, the cost of one square meter is falling.

Going beyond the limits of the geometric center reduces the value of the property. However, the value of the object is increased due to the benefits of location (transport nodes, objects of social attraction) and causes an increase in its value.

In the end, we can conclude that, in general, increasing level of the transport accessibility of the territory is, in our country, one of the key factors of economic growth. The availability of tools that allow carrying out a detailed and accurate assessment of accessibility is now one of the most important scientific studies conducted in the framework of transport and urban planning.

\section{References}

1. Yu. S. Lantsberg, Yu. A. Stavnichy, Guidelines for the design of city streets and roads (Stroyizdat, Moscow, 1980)

2. E. V. Palagin, Terminological dictionary on construction in 12 languages (Russian language, Moscow, 1986)

3. D. Friedman, N. Ordway, Analysis and evaluation of income-producing real estate / (Case, Moscow, 1997)

4. SNIP 2.07.01-89, Town planning: planning and development of urban and rural settlements (Center for Strategic Planning of the USSR Gosstroy, Moscow, 1994) 
5. VO Dubovik, Regional Studies, 4(42) (2013)

6. A. Yu. Mikhailov, A. G. Levashev, M. I Sharov, Modern methods for assessing the quality of traffic management in cities (Irkutsk, 2015)

7. M. Sharov, A. Levashev, A. Mikhailov, WIT Transactions on Ecology and the Environment, 1, 651-660 (2014)

8. M. Sharov, A. Mikhailov, Papers presented at the Transportation Research Procedures, 20, 591-595 (2017)

9. A. I. Fedotov, N. Y. Kuznetsov, A. V. Lysenko, V. G. Vlasov, AIP Conference Proceedings (2017)

10. A. Yu. Mikhailov, M. I. Sharov, Izvestiya Volgograd State Technical University. Series: Terrestrial transport systems, 9(19), 64-66 (2014)

11. R. G. Mugion, M. Toni, H. Raharjo, L. Di Pietro, S.P. Sebathu, Journal of Cleaner Production, 174, 1566-1587 (2018)

12. S. Mlynarski, R. Pilch, M. Smolnik, Eksploatacja i Niezawodnosc-Maintenance and Reliability, 20(2), 278-283 (2018)

13. D. V. Lierop, M. G. Badami, A. M. El-Geneidy, Transport Reviews, 38(1), 52-72, (2018)

14. M. M. Nesheli, A. Ceder, R. Brissaud, Transportation, 44(5), 957-975 (2017)

15. X. Fu, Z. Juan, Transportation, 44(5), 1021-1042 (2017)

16. E. Yu. Podoskina, Y. Yu. Mikhailukova, Scientific Almanac, 1-1(15), 218-222 (2016)

17. E. N. Kovaleva, Journal of the University of Water Communications, 3, 171-175 (2011)

18. V. A. Gudkov, N. V. Dulina, V. V. Tokarev, Freight and Passenger Carrier, 4, 29-33 (2009)

19. P. M. Sapanov, Geodesy and Cartography, 12, 15-21 (2015)

20. S. A. Yatsenko, S. V. Kolganov, Bulletin of the Irkutsk State Technical University, 5(64), 122-128 (2012) 